\title{
Probing the Growth Kinetics for the Formation of Uniform 1D Block Copolymer Nanoparticles by Living Crystallization-Driven Self-Assembly
}

\author{
Charlotte E. Boott, ${ }^{\dagger, \phi}$ Erin M. Leitao, ${ }^{\dagger, \phi}$ Dominic W. Hayward, ${ }^{\dagger}$ Romain F. Laine, ${ }^{\S}$ Pierre Mahou, ${ }^{\S}$ \\ Gerald Guerin, ${ }^{\psi}$ Michell A. Winnik, ${ }^{\psi}$ Robert M. Richardson, ${ }^{*} *$ Clemens F. Kaminski, ${ }^{\S, *}$ \\ George R. Whittell, ${ }^{\dagger} * *$ and Ian Manners ${ }^{\dagger} * *$ \\ †School of Chemistry, University of Bristol, Cantock’s Close, Bristol, BS8 1TS, U.K. \\ ${ }^{\ddagger}$ School of Physics, University of Bristol, Tyndall Avenue, Bristol, BS8 1TL, U.K. \\ ${ }^{\S}$ Department of Chemical Engineering and Biotechnology, University of Cambridge, Philippa \\ Fawcett Drive, Cambridge, CB3 OAS, U.K. \\ ${ }^{\psi}$ Chemistry Department, University of Toronto, 80 St. George Street, Toronto, M5S 3H6, Canada \\ ${ }^{\phi}$ These authors contributed equally
}

\begin{abstract}
Living crystallization-driven self-assembly (CDSA) is a seeded growth method for crystallizable block copolymers (BCPs) and related amphiphiles in solution and has recently emerged as a promising and versatile route to uniform core-shell nanoparticles (micelles) with control of dimensions and architecture. However, the factors that influence the rate of micelle growth have not been systematically studied. Using transmission electron microscopy (TEM), together with the superresolution fluorescence microscopy techniques of stimulated emission depletion (STED) microscopy and single molecule localization microscopy (SMLM), we have investigated the kinetics of the seeded growth of poly(ferrocenyldimethylsilane)- $b$-(polydimethylsiloxane) (PFS- $b$-PDMS), to form cylindrical micelles as this is the prototypical living CDSA system. By altering various self-assembly parameters including concentration, temperature, solvent, and BCP composition our results have established that the time taken to prepare cylindrical micelles via the living CDSA method can be reduced by decreasing temperature, by employing solvents that are poorer for the crystallizable PFS
\end{abstract}


core-forming block, and by increasing the length of the PFS core-forming block. These results are likely to be generally useful for the future optimization of a wide variety of living CDSA systems. Our studies also demonstrate that the growth kinetics for living CDSA do not exhibit the first order dependence of growth rate on unimer concentration anticipated by analogy with living covalent polymerizations of molecular monomers. This difference may be caused by the combined influence of chain conformational effects of the BCP on addition to the seed termini, and chain length dispersity.

\section{Introduction}

A key scientific challenge of widespread current interest involves the creation of well-defined functional materials based on soft matter that exist on a length-scale of nanometers to microns. ${ }^{1-5}$ One key strategy employed to achieve this goal is the solution processing of block copolymers (BCPs) with amorphous core-forming segments, which produces core-shell nanoparticles (micelles) with a range of morphologies and functionalities. ${ }^{6,7}$ This has resulted in a variety of actual and potential applications from drug delivery to composite reinforcement. ${ }^{8-11}$ Nevertheless, a major problem in this field is the limited ability to create uniform samples of micellar nanoparticles with predictable and anisotropic shape, tunable dimensions, and controllable spatially-confined core and/or corona chemistries.

The solution self-assembly of BCPs with a crystallizable core-forming block has recently emerged as a powerful route to core-shell nanoparticles with high levels of precision and control. Upon addition of a selective solvent for the corona-forming block to a molecularly dissolved BCP (unimer), both crystallization of the core-forming block and amphiphilicity influence micelle formation, with low curvature morphologies, such as cylinders and platelets, normally being favoured. This process has now been studied for a wide range of BCPs with different crystallizable coreforming segments and has been termed crystallization-driven self-assembly (CDSA). ${ }^{12}$

Length control can be achieved using a CDSA approach through the application of seeded growth $^{13}$ techniques to produce low dispersity micelles. For example, previous work has shown that the exposed crystal faces at the termini of pre-existing cylindrical micelles with a crystalline poly(ferrocenyldimethylsilane) $(\mathrm{PFS})^{14}$ core remain active to further growth via epitaxy. ${ }^{15}$ This 
technique can then be used to prepare monodisperse micelles of controlled length by the addition of a known amount of unimer to a colloidal solution of small crystallite seeds, generated by the sonication of multimicron long cylindrical micelles (Scheme 1). ${ }^{13}$ The control of length through variation of the unimer-to-seed ratio can be considered to be analogous to molecular weight control in a living covalent chain growth polymerization, and the process has thus been termed living CDSA. Using this seeded growth approach, the sequential addition of BCPs with a common crystallizable core-forming block,${ }^{15}$ or different core blocks with a small lattice mismatch, ${ }^{16}$ results in the formation of a range of multicompartment block comicelles with nanosegregated functionality. ${ }^{17,18}$ A variety of BCPs with different crystallizable core-forming blocks have been shown to undergo living CDSA ${ }^{14,16,19-21}$ and the process has been extended to amphiphiles that form supramolecular polymers. ${ }^{22}$ For the BCPs, those with a PFS core-forming block have been the most widely studied to date. Living CDSA of PFS BCPs has recently been shown to be scalable ${ }^{23}$ and to enable the preparation of a wide range of $\mathrm{BCP}$ nanoparticles, including 2D platelets, ${ }^{24,25}$ non-centrosymmetric ${ }^{26}$ and branched cylinders $^{27}$ and hierarchical structures, such as supermicelles ${ }^{28,29}$ and superlattices. ${ }^{30}$ Furthermore, a key feature of the resulting crystalline $\mathrm{BCP}$ assemblies is that a high barrier exists to unimer exchange between micelles at near ambient temperatures, which prevents equilibration, and the consequential loss of uniformity and complexity.

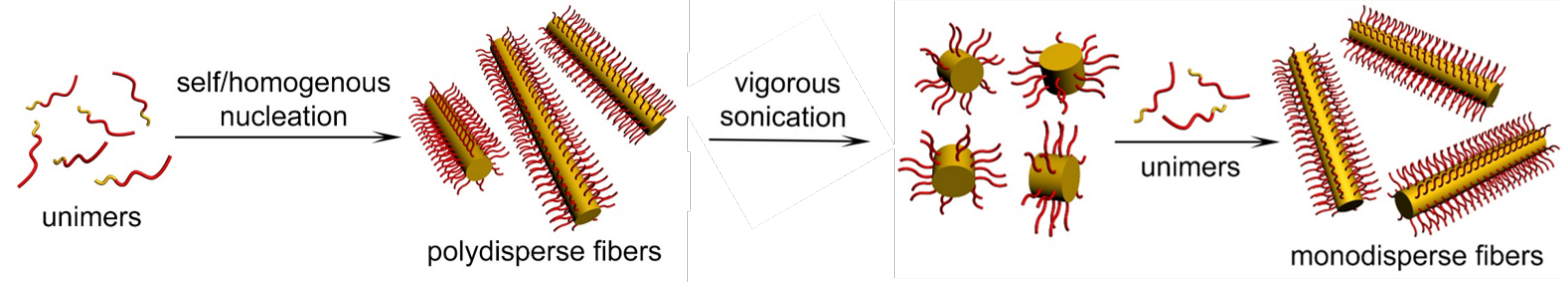

Scheme 1: Schematic representation of the preparation of monodisperse cylindrical micelles via seeded growth living CDSA.

Although many studies have now demonstrated the high levels of control possible using living CDSA, and that the epitaxial nature of the seeded growth process has been established for the cases of both $1 \mathrm{D}$ and $2 \mathrm{D}$ growth, ${ }^{25,31-33}$ the factors that influence the kinetics of the growth process are virtually unexplored. In a recent study we analyzed the formation of cylindrical micelles via the seeded growth of PFS-based linear and brush BCPs with chemically similar structures but different 
degrees of coronal steric bulk. ${ }^{18}$ After addition of the BCPs to pre-existing seeds, the lengths of cylindrical micelles were monitored as a function of time using transmission electron microscopy (TEM). It was found that the growth rates were substantially reduced by increasing steric bulk of the corona-forming block.

In this paper we report the use TEM to monitor the growth of different PFS BCPs under a variety of conditions in order to obtain key fundamental information on the growth process. These methods are augmented by super-resolution fluorescence microscopy (SRFM) techniques, which are able to image individual nanoparticles in solution. In recent years, SRFM techniques such as structured illumination microscopy (SIM), ${ }^{34,35}$ stimulated emission depletion microscopy (STED) $)^{36-38}$ and single molecule localization microscopy (SMLM) ${ }^{36,39-43}$ have emerged as impressive methods with which to visualize biological structures and their growth. ${ }^{44}$ For example, the formation of amyloid fibres has been studied in cells ${ }^{45,46}$ and aqueous solution ${ }^{47,48}$ using super-resolution techniques and a two-colour SMLM approach has been used to elucidate the growth kinetics of individual fibrils in vitro. ${ }^{44,49,50}$ Furthermore, in recent work SMLM has been used to observe dynamic exchange mechanism of supramolecular polymeric fibres, providing unprecedented examples of the utility of these techniques to study non-covalent polymerizations. ${ }^{51,52}$ We have also recently demonstrated the use of STED and two-colour SMLM to image PFS-based BCP micelles in organic media, which demonstrated that the length data obtained by TEM analysis on dried samples is representative of the micelles in their native environment. ${ }^{53}$ Based on these considerations, as complementary experiments to TEM, the SRFM techniques, STED and two-colour SMLM are employed to study the growth by living CDSA in solution. In addition, our micelle growth data were fitted to kinetics models, which enabled rate constants to be extracted quantitatively and detailed information on the living CDSA growth process to be obtained.

\section{Results}

\section{Monitoring the growth of $\mathrm{PFS}_{63}-b-\mathrm{PDMS}_{513}$ one-dimensional micelles by TEM}

In a typical living CDSA experiment, a $\mathrm{PFS}_{63}-b-\mathrm{PDMS}_{513}{ }^{54}[\mathrm{PDMS}=$ polydimethylsiloxane, subscripts indicate the number average degree of polymerization $\left.\left(\mathrm{DP}_{\mathrm{n}}\right)\right]$ unimer solution in THF was 
added to a solution of crystallite seed micelles, prepared by sonication of longer cylindrical micelles, in a selective solvent for the corona-forming block. A range of parameters were subsequently varied including temperature, concentration, selective solvent and percentage common solvent. To monitor the effect of each of these parameters on the growth of $\mathrm{PFS}_{63}-b-\mathrm{PDMS}_{513} \mathrm{BCP}$ micelles, aliquots were taken from the reaction mixtures at set time points, placed on carbon-coated copper grids and analyzed by TEM. This enabled the micelle length at different time points throughout the growth process to be determined.

\section{The crystalline core structure of PFS BCP micelles}

The key feature of PFS-based BCP micelles is the crystalline PFS core. Previous studies using wide-angle X-ray scattering (WAXS) of $\mathrm{PI}_{637}-b-\mathrm{PFS}_{53}$ cylindrical micelles $(\mathrm{PI}=$ polyisoprene) have shown that the PFS chains extend perpendicular to the long axis of the micelle and pack with pseudo hexagonal symmetry. ${ }^{31}$ Further studies involving micelles from a range of different PFS-containing BCPs suggest that increasing the core chain length results in the core cross-section becoming more elliptical, but the core structure remains broadly unchanged. 55,56 The majority of experiments discussed herein involve the use of the same PFS-containing BCP, namely, $\mathrm{PFS}_{63}-b-\mathrm{PDMS}_{513}$. This enabled us to investigate whether the factors that influence the micelle growth rate also had a simultaneous effect on the micelle cross-section. For the BCP used in these experiments, both short $\left(L_{\mathrm{n}}=92 \mathrm{~nm}, \mathrm{PDI}=L_{\mathrm{w}} / L_{\mathrm{n}}=1.07\right.$, where $L_{\mathrm{n}}$ and $L_{\mathrm{w}}$ represent the number/weight average contour length, $)$ and long $\left(L_{\mathrm{n}}=1757 \mathrm{~nm}\right.$, PDI $\left.=1.01\right)$ low polydispersity micelles were prepared by seeded growth, and the micelle widths were analyzed by small- and wide-angle X-ray scattering (SAXS and WAXS) and TEM (Figure S1). The SAXS data for both sets of micelles afforded identical core radii of $3.8 \mathrm{~nm}$ and corona widths of $17.4 \mathrm{~nm}$ and $19.6 \mathrm{~nm}$ for the short and long micelles, respectively (Table S1). Analysis by high-resolution TEM, however, revealed number average contour widths, $W_{\mathrm{n}}$, of $11 \mathrm{~nm}$ for both samples. We view $W_{\mathrm{n}}$, as determined by TEM, to predominantly reflect the core width, meaning therefore that a small discrepancy exists with the value obtained $(7.6 \mathrm{~nm})$ by X-ray methods. This is most probably due to a densification of the corona at the core-corona interface on drying, leading to a larger apparent core width in the dry state. These results demonstrated that the 
micellar structure does not change with contour length and the linear aggregation number (i.e. the number of PFS BCP molecules per unit length) is constant at 2.5 chains/nm (see Supporting Information page 7$).^{57}$

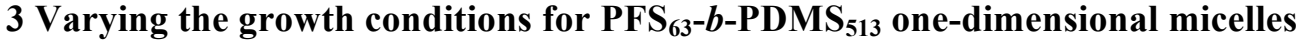

\subsection{Effect of initial unimer concentration}

The overall length of cylindrical micelles formed in living CDSA seeded growth experiments is proportional to the unimer-to-seed ratio. This is analogous to living covalent polymerizations in which the chain length is dependent on the ratio of monomer to initiator. It was therefore of interest to investigate whether this analogy also applied to the reaction kinetics. In a living covalent polymerization the reaction is first order in both monomer and initiator concentrations, ${ }^{58}$ and this would translate to the reaction being first order in both unimer, $[U]$, and seed, $[S]$, concentrations for living CDSA. As the latter remains constant during the course of the reaction, and initiation occurs from both ends of the seed, $[S]$ should be substituted by $2[S]_{0}$ (the concentration at $t=0$ ) in the differential form of the rate equation (Eq. 1).

$$
\frac{d[U]}{d t}=-k[U] 2[S]_{0} \quad \text { Eq. } 1
$$

Integrating Eq. 1 then affords an expression for the concentration of unimer as a function of time, $[U(t)]$, in terms of the initial concentrations (Eq. 2).

$$
[U(t)]=[U]_{0} e^{-2 k[S]_{0} t} \text { Eq. } 2
$$

Determining the concentrations of micelle and unimeric BCP in solution, however, is problematic. We therefore chose to monitor the reaction kinetics by determining the average length, $L(t)$, of the individual micelles formed, which could be measured microscopically. The total length grown over all micelles, $L_{\text {tot }}(t)$, is related to the concentrations of unimer, $[U(t)]$ and $U_{0}$, the volume of solution, $V$, and the linear aggregation number (number of BCP molecules per unit length), $N_{a g g}$ (Eq. 3). We have shown (vide supra) that the latter is constant with micelle length, under the growth conditions used.

$$
[U(t)]=[U]_{0}-\frac{L_{t o t}(t) N_{a g g}}{N_{A} V} \quad \text { Eq. } 3
$$


Rearranging Eq. 3 to make $L_{\text {tot }}(t)$ the subject and dividing by the number of micelles, which for a living process equals the number of seeds, $N_{\text {seed }}$, then affords an expression for the length grown $L_{\text {grown }}(t)$ for each micelle (Eq. 4).

$$
L_{\text {grown }}(t)=\frac{1}{N_{\text {seed }}} \frac{N_{A} V}{N_{\text {agg }}}[U]_{0}\left(1-e^{-2 k[S]_{0} t}\right) \quad \text { Eq. } 4
$$

$N_{\text {seed }}$ is related to $[S]_{0}$ (Eq. 5), and this leads to Eq.6.

$$
\begin{gathered}
N_{\text {seed }}=[S]_{0} N_{A} V \quad \text { Eq. } 5 \\
L_{\text {grown }}(t)=\frac{1}{N_{\text {agg }}} \frac{[U]_{0}}{[S]_{0}}\left(1-e^{-2 k[S]_{0} t}\right)
\end{gathered}
$$

The experimentally determined length, $L(t)$, however, also includes that of the seed, $L_{\text {seed, }}$ and this needs to be taken into account in the final model (Eq. 7).

$$
L(t)=\frac{1}{N_{\text {agg }}} \frac{[U]_{0}}{[S]_{0}}\left(1-e^{-2 k[S]_{0} t}\right)+L_{\text {seed }} \quad \text { Eq. } 7
$$

We investigated the effect of initial unimer concentration on the growth of $\mathrm{PFS}_{63}-b-\mathrm{PDMS}_{513}$ cylindrical micelles. Varying the initial unimer concentration (from 10 to $30 \mathrm{mg} / \mathrm{mL}$ ) while keeping the concentration of common solvent and seed concentration constant, resulted in different unimer-toseed ratios and therefore different final micelle lengths. Despite having different final lengths $\left(L_{\mathrm{n}}=\right.$ 613, 982 and $1798 \mathrm{~nm}$ for initial unimer concentrations of 10,20 and $30 \mathrm{mg} / \mathrm{mL}$, respectively) we expected all micelles to have the same linear aggregation number based on the SAXS/WAXS data for the short and long cylindrical micelles discussed above. The time required for the micelles to reach their final length, however, was approximately the same for all 3 experiments (Figure 1 and 2a).

If Eq. 7 correctly describes the micellar length as a function of time, then a plot of the logarithm of $L_{\infty}-L(t)$, which approximates to $L_{\text {final }}-L(t)$, versus $t$ should generate a straight line. This, however, was not found to be the case ( $\mathrm{r}$-squared $=0.61-0.82)$ and neither did the data afford a straight-line plot for $1 /\left(L_{\text {final }}-L(t)\right)$ versus $t(\mathrm{r}$-squared $=0.86-0.94)$, which would be characteristic of a second order reaction (Figure 1). Non-integer reaction orders can be evaluated by the initial rates method, which involves analysis of the linear region of the $L_{\text {final }}-L(t)$ vs. $t$ plot (Figure S2). A log-log plot of these rates $v s .[U]_{0}$ then yields the reaction order as the gradient of the line (Figure S3). This 
method gave an order of $1.16 \pm 0.25$ with respect to the concentration of unimer, which contrary to the $\ln \left(L_{\text {final }}-L(t)\right)$ vs. $t$ plot suggests that the reaction is first-order. This discrepancy, however, is most likely a result of the reduced data set used in the initial rates method, which does not capture the larger deviation from first-order behaviour that occurs at later time points. We therefore explored other data fitting approaches to extract rate information from our experimental data.
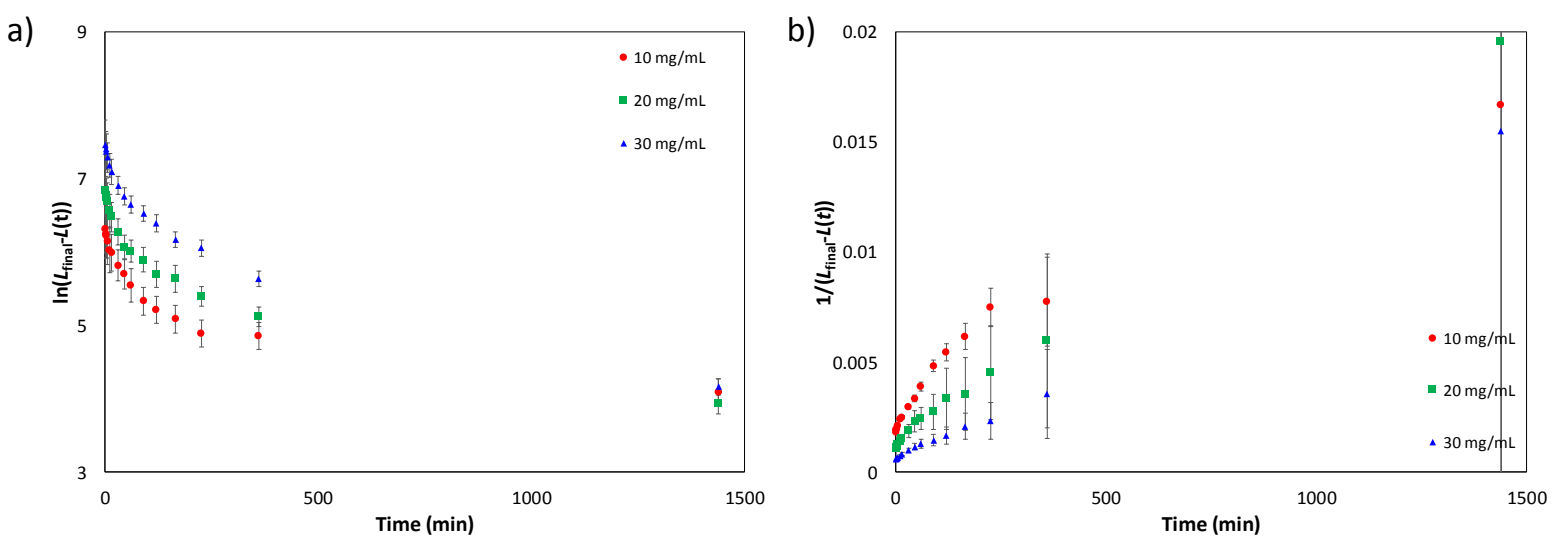

Figure 1: Lengths of $\mathrm{PFS}_{63}-b-\mathrm{PDMS}_{513}$ micelles as a function of time, monitored over a period of $24 \mathrm{~h}$ after the addition of unimer to $\mathrm{PFS}_{63}-b-\mathrm{PDMS}_{513}$ seed micelles, $\left(L_{\mathrm{n}}=57 \mathrm{~nm}, L_{\mathrm{w}} / L_{\mathrm{n}}=1.11\right)$, a) first order plot of $\ln \left(L_{\text {final }}-L(t)\right)$ versus time for different unimer concentrations b) second order plot of $1 /\left(L_{\text {final }}-L(t)\right)$ versus time for different unimer concentrations. Error bars propagated from $\pm \sigma$ (standard deviation) of the micelle $L_{\mathrm{n}}$.

\subsection{Effect of seed concentration}

We investigated the effect of seed concentration $\left(1.0 \times 10^{-2}, 6.7 \times 10^{-3}\right.$ and $\left.3.3 \times 10^{-3} \mathrm{mg} / \mathrm{mL}\right)$ while keeping the initial concentration of unimer and common solvent constant. This resulted in different unimer-to-seed ratios and therefore different final micelle lengths, in a similar manner to varying the initial unimer concentration. The time required for the micelles to reach their final length, however, was slightly different for the 3 concentrations, and the precise form of this data will be discussed in detail in Section 3.3.

Eq. 1 indicates that the rate of unimer consumption should be first order in $[S]$, if the reaction kinetics are analogous to those of a living covalent polymerisation. With regards to the rate of micelle growth, however, the situation is slightly different. Differentiating Eq. 7 and examining the initial rate $\left(2 k[S]_{0} t \ll 1\right)$ demonstrates that $\mathrm{dL} / \mathrm{dt} \simeq 2[U]_{0} k / N_{\mathrm{agg}}$, which is independent of $[S]_{0}$. The condition of 
constant $[U]_{0}$ required to probe the effect of varying $[S]_{0}$, however, is also only true at low extents of growth. We therefore determined initial rates at each seed concentration (Figure S4), and represented the data as a function of $[S]_{0}$ in the form of a log-log plot (Figures S5). This afforded a reaction order of $-0.75 \pm 0.05$ in the concentration of seeds, which is not consistent with the expected zero-order kinetics of micelle growth. The method of initial rates can have limitations in that reaction complexities may not be reflected over the short time-frame that the initial rate can be extracted. We therefore sought a model that could fit the data over the whole course of the reaction.

\subsection{Data Fitting}

To model the change in micelle length with time we attempted to fit the data with single, double, triple, and stretched exponential functions (see Supporting Information, page 14 for more details). A single exponential resulted in underestimation of the final micelle length, as expected from the non-linear nature of the $\ln \left(L_{\text {final }}-L(t)\right)$ vs. $t$ plot (Figure 1a). Furthermore, a triple exponential resulted in data over-fitting and therefore large uncertainties associated with the fitted parameters. Both the double and stretched exponential functions enabled us to fit the data well, producing reduced r-squared values of greater than 0.95 . To determine which equation consistently gave the better fit, we compared the two models using Akaike's and the Bayesian information criterion tests. In over $80 \%$ of cases the stretched exponential was found to provide a better fit of the data ( $r$-squared values $>0.98$ all cases), and for the situations where the double exponential was favoured, the difference in reduced r-squared values for the two models was found to be less than $0.5 \%$ (Table S2). As the former involved fewer fitted parameters, we concluded that it gave a satisfactory description of the underlying chemical reaction, and that the introduction of further parameters was not justified. The stretched exponential takes the form shown in Eq. 8, where $L(t)$ is the micelle length as a function of time, $A$ is final micelle length minus seed length, $k$ ' is the rate constant, $b$ is the fractional power of the exponential, which describes the deviation from a true single exponential and $L_{\text {seed }}$ is the seed length (a constant). The contour length for each batch of seeds prepared was measured prior to the kinetics experiments and therefore $L_{\text {seed }}$ is fixed as this predetermined value in Eq. 8 (See Supporting Information page 8 for more details). 


$$
L(t)=A\left(1-e^{-\left(k^{\prime} t\right)^{b}}\right)+L_{\text {seed }} \quad \text { Eq. } 8
$$

Employing Eq. 8 to model the change in length as of function time for different unimer concentrations (Figure 2a, c) affords $k^{\prime}$ values of $1.81 \pm 0.19 \times 10^{-4}, 2.13 \pm 0.23 \times 10^{-4}$ and $1.91 \pm 0.15 \times 10^{-4}$ $\mathrm{s}^{-1}$ for $[U]_{0}$ values of 10,20 and $30 \mathrm{mg} / \mathrm{mL}$, respectively. These rate constants are the same within experimental error. It is noteworthy that the $b$ values, which are $0.57,0.60$ and 0.58 for 10,20 and 30 $\mathrm{mg} / \mathrm{mL}$, respectively, are also the same to within experimental error.

For the initial seed concentration data (Figure 2b, d), a fit of Eq. 8 produces $k^{\prime}$ values of $1.81 \pm 0.19 \times 10^{-4}, 1.80 \pm 0.26 \times 10^{-4}$ and $1.26 \pm 0.14 \times 10^{-4} \mathrm{~s}^{-1}$ for $[S]_{0}$ values of $1.0 \times 10^{-2}, 6.7 \times 10^{-3}$ and $3.3 \times 10^{-3} \mathrm{mg} / \mathrm{mL}$. Although the rate constants at the highest 2 concentrations area almost identical when the experimental errors are considered, that at the lowest concentration is significantly lower. Comparison of Eqs. 7 and 8, however, show that $k^{\prime}=2 k[S]_{0}$, and therefore, unlike the case with $\left[U_{0}\right.$, $k^{\prime}$ is not independent of $[S]_{0}$. Nonetheless, when $k^{\prime}$ is converted to the $[S]_{0}$ independent rate constant, $k$, values of $0.009 \pm 0.001,0.013 \pm 0.002$ and $0.019 \pm 0.002 \mathrm{~mL} / \mathrm{mg} . \mathrm{s}$ are obtained for initial concentrations of $1.0 \times 10^{-2}, 6.7 \times 10^{-3}$ and $3.3 \times 10^{-3} \mathrm{mg} / \mathrm{mL}$, respectively. The reasons for this behaviour are currently unclear, although the inverse relationship between $k$ and $[S]_{0}$ is not what would be expected if the process were diffusion limited, nor if there were systematic error in $[S]_{0}$. The fits also afford values of $0.57 \pm 0.02,0.62 \pm 0.03$ and $0.62 \pm 0.02$ for $b$, of which the former 2 are the same within experimental error with $b$ at the lowest concentration marginally larger than that at the highest.

a)

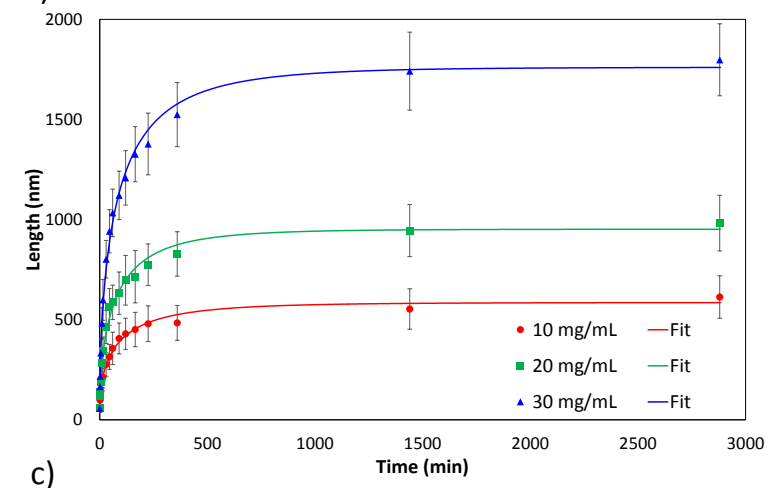

b)

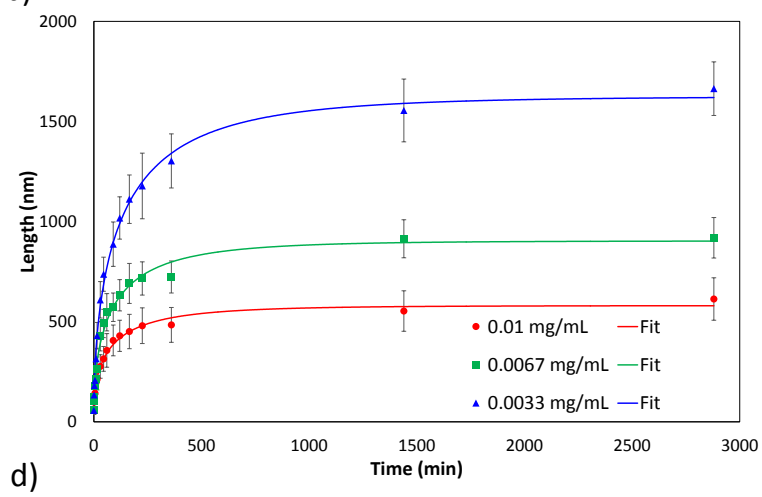

\begin{tabular}{|c|c|c|c|c|c|c|c|c|c|c|c|c|c|}
\hline \begin{tabular}{|c|}
$\begin{array}{c}\text { Unimer } \\
\text { concentration }\end{array}$ \\
\end{tabular} & $A(n m)$ & $\begin{array}{l}\text { Error } \\
(\mathrm{nm})\end{array}$ & $k^{\prime}\left(s^{-1}\right)$ & Error $\left(\mathrm{s}^{-1}\right)$ & b & Error & $\begin{array}{c}\text { Seed } \\
\text { concentration }\end{array}$ & $A(n m)$ & $\begin{array}{l}\text { Error } \\
\text { (nm) }\end{array}$ & $k^{\prime}\left(s^{-1}\right)$ & Error $\left(\mathrm{s}^{-1}\right)$ & b & Error \\
\hline $10 \mathrm{mg} / \mathrm{mL}$ & 528 & 13 & $1.81 \times 10^{-4}$ & $1.9 \times 10^{-5}$ & 0.57 & 0.02 & $1.0 \times 10^{-2} \mathrm{mg} / \mathrm{mL}$ & 528 & 13 & $1.81 \times 10^{-4}$ & $1.9 \times 10^{-5}$ & 0.57 & 0.02 \\
\hline $20 \mathrm{mg} / \mathrm{mL}$ & 888 & 23 & $2.13 \times 10^{-4}$ & $2.3 \times 10^{-5}$ & 0.60 & 0.02 & $6.7 \times 10^{-3} \mathrm{mg} / \mathrm{mL}$ & 826 & 61 & $1.80 \times 10^{-4}$ & $2.6 \times 10^{-5}$ & 0.62 & 0.03 \\
\hline $30 \mathrm{mg} / \mathrm{mL}$ & 1696 & 34 & $1.91 \times 10^{-4}$ & $1.5 \times 10^{-5}$ & 0.58 & 0.02 & $3.3 \times 10^{-3} \mathrm{mg} / \mathrm{mL}$ & 1553 & 49 & $1.26 \times 10^{-4}$ & $1.4 \times 10^{-5}$ & 0.62 & 0.02 \\
\hline
\end{tabular}


Figure 2: Lengths of $\mathrm{PFS}_{63}-b-\mathrm{PDMS}_{513}$ micelles as a function of time, monitored over a period of 2 days after the addition of unimer to $\mathrm{PFS}_{63}-b-\mathrm{PDMS}_{513}$ seed micelles, $\left(L_{\mathrm{n}}=57 \mathrm{~nm}, L_{\mathrm{w}} / L_{\mathrm{n}}=1.11\right)$ for a) variable unimer concentration and b) variable seed concentration. c, d) Table of kinetic data for a) variable unimer concentration, b) variable seed concentration, respectively, $A(\mathrm{~nm})=$ final micelle length minus seed side. a, b) Error bars $= \pm \sigma$ (standard deviation) of the micelle $L_{\mathrm{n}} . \mathrm{c}, \mathrm{d}$ ) Standard errors for the values $A, k^{\prime}$, and $b$ obtained from the fit of Eq. 8 to data.

\subsection{Effect of temperature}

To explore the effect of temperature on the growth process, living CDSA experiments involving the addition of $\mathrm{PFS}_{63}-b-\mathrm{PDMS}_{513}$ to crystallite seeds of the same BCP $\left(L_{\mathrm{n}}=57 \mathrm{~nm}\right)$ were performed at 7 different temperatures; 5, 10, 15, 21, 28, 35 and $42{ }^{\circ} \mathrm{C}$. Elevating the self-assembly temperature increased the length of time required for the micelles to reach their final lengths (Figure 3a and S6) with concomitant reductions in $k^{\prime}$ from $9.09 \times 10^{-4}$ to $1.21 \times 10^{-5} \mathrm{~s}^{-1}$ (Figure 3b). There was also a general trend for a reduction in the $b$ values $(0.68$ to 0.47$)$ and final micelle length achieved with increasing temperature. Specifically, the final micelle length decreased from $3314 \pm 279 \mathrm{~nm}$ to $1764 \pm 209 \mathrm{~nm}$, as the temperature was increased from 5 to $42{ }^{\circ} \mathrm{C}$. The most likely cause of this change would be an increase in micellar width and, consequently, in $N_{\text {agg }}$ with temperature. This is similar to the reported thickening in the chain axis direction of homo- and random copolymer crystals on thermal annealing. ${ }^{59,60}$ Indeed, SAXS/WAXS on the final micelle solutions revealed an increase in core radius, $r_{\text {core }}$, from $3.36 \mathrm{~nm}$ to $4.43 \mathrm{~nm}$ on increasing the temperature from 5 to $42{ }^{\circ} \mathrm{C}$ (Figure $\mathrm{S} 7$ and Table S3). It would be expected that the increase in $r_{c o r e}{ }^{2}$ would scale with the decrease in $L$, if this were the sole contributor. This appeared to be the case with the length decreasing by $45 \%$ over this series of temperatures: a value comparable to the corresponding change in $r_{\text {core }}{ }^{2}$ of $42 \%$. Furthermore, WAXS indicated that the inter-chain spacing within the cores of the two different micellar samples was the same (Figure S7c). From the rate constants for the experiments at different temperatures we were able to generate an Eyring plot to determine the mean activation enthalpy, entropy and free energy for the reaction (from the data presented in Figure 3a). This provided negative 
values for the enthalpic and entropic activation terms (Figure S17) of $-89.0 \mathrm{~kJ} / \mathrm{mol}$ and $-619 \mathrm{~J} / \mathrm{mol}$, respectively.

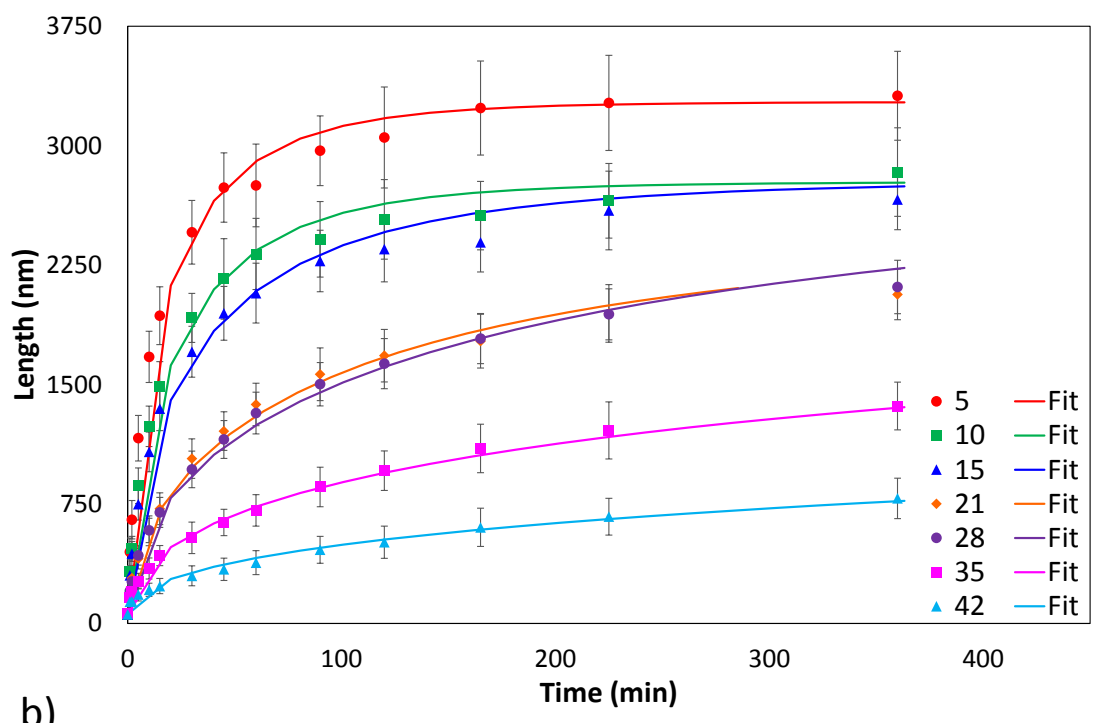

b)

\begin{tabular}{|c|c|c|c|c|c|c|}
\hline Temp $\left({ }^{\circ} \mathbf{C}\right)$ & $\mathbf{A}(\mathbf{n m})$ & Error $(\mathbf{n m})$ & $\mathbf{k}^{\prime}\left(\mathbf{s}^{-1}\right)$ & Error $\left(\mathbf{s}^{-1}\right)$ & $\mathbf{b}$ & Error \\
\hline 5 & 3177 & 44 & $9.09 \times 10^{-4}$ & $5.4 \times 10^{-5}$ & 0.68 & 0.02 \\
10 & 2630 & 42 & $7.51 \times 10^{-4}$ & $4.8 \times 10^{-5}$ & 0.70 & 0.02 \\
15 & 2630 & 51 & $5.18 \times 10^{-4}$ & $4.2 \times 10^{-5}$ & 0.64 & 0.02 \\
21 & 2404 & 52 & $1.67 \times 10^{-4}$ & $1.4 \times 10^{-5}$ & 0.60 & 0.02 \\
28 & 2817 & 42 & $9.38 \times 10^{-5}$ & $6.1 \times 10^{-6}$ & 0.55 & 0.01 \\
35 & 2161 & 32 & $3.85 \times 10^{-5}$ & $2.9 \times 10^{-6}$ & 0.50 & 0.01 \\
42 & 1698 & 60 & $1.21 \times 10^{-5}$ & $2.1 \times 10^{-6}$ & 0.47 & 0.01 \\
\hline
\end{tabular}

Figure 3: a) Lengths of $\mathrm{PFS}_{63}-b-\mathrm{PDMS}_{513}$ micelles as a function of time, monitored over a period of $6 \mathrm{~h}$ after the addition of unimer to $\mathrm{PFS}_{63}-b-\mathrm{PDMS}_{513}$ seed micelles $\left(L_{\mathrm{n}}=57 \mathrm{~nm}, L_{\mathrm{w}} / L_{\mathrm{n}}=1.11\right)$. b) Table of kinetic data for variable temperature studies. a) Error bars $= \pm \sigma$ (standard deviation) of the micelle $L_{\mathrm{n}}$. b) Standard errors for the values $A, k^{\prime}$, and $b$ obtained from the fit of Eq. 8 to data.

\subsection{Effect of solvent}

To investigate the effect of common solvent on the growth kinetics, 3 different THF compositions were examined, namely $2.3,4.7$ and $9.6 \% \mathrm{v} / \mathrm{v}$ THF in $n$-hexanes. As the THF content increased, the growth rate of the micelles slowed as evidenced by $k^{\prime}=1.56 \times 10^{-2}, 3.04 \times 10^{-3}$ and $4.57 \times 10^{-4} \mathrm{~s}^{-1}$ for $2.3,4.6$ and $9.7 \% \mathrm{v} / \mathrm{v}$ THF, respectively (Figure $4 \mathrm{a}, \mathrm{c}$ and S8 and S9). This reduction in rate constant, however, is accompanied by an increase in $b$, which is the opposite of the trend 
observed for the experiments performed at different temperature. Furthermore, as all experiments showed convergence to constant final $L$, a change in linear aggregation number with length, upon changing solvent composition, is unlikely.

In order to probe the role of the selective solvent on the rate of the self-assembly process, solvents with differing solubility parameters were chosen: $n$-hexanes $\left(14.9 \mathrm{MPa}^{1 / 2}\right), n$-heptane $(15.3$ $\left.\mathrm{MPa}^{1 / 2}\right)$, and ethyl acetate $\left(18.2 \mathrm{MPa}^{1 / 2}\right) \cdot{ }^{61}$ Other solvents were also explored, but it proved difficult to analyze the resulting micelles by TEM, due to severe aggregation or fragmentation upon drying (see Supporting Information, page 20 for more details). The rate constants decreased on exchanging $n$ hexanes for $n$-heptane and then ethyl acetate $\left(k^{\prime}=6.32 \times 10^{-3}, 3.45 \times 10^{-3}\right.$ and $1.75 \times 10^{-5} \mathrm{~s}^{-1}$, respectively), whilst maintaining a constant THF composition of $4.8 \% \mathrm{v} / \mathrm{v}$. These experiments demonstrated that as the medium becomes a less poor solvent for the insoluble core-forming PFS block $\left(18.7 \mathrm{MPa}^{1 / 2}\right.$, PDMS $\left.=14.9 \mathrm{MPa}^{1 / 2}\right),{ }^{62}$ the rate constant decreases (Figure $4 \mathrm{~b}, \mathrm{~d}$ and $\mathrm{S} 10$ ). Although the series: $n$-hexanes, $n$-heptane, and ethyl acetate became concomitantly poorer for the PDMS corona-forming block, there was no evidence of reverse micelle formation or any decrease in the colloidal stability of the resulting micelles. This suggests that the effect of the solvent on the crystallization of the core is more significant in determining the rate constant than the change in amphiphilicity of the copolymer. A trend of increasing $b$ as the solvent medium became better for PFS was also observed, similar to that for the experiments with different concentrations of common solvent (THF). Once again, the similar final micelle lengths suggested that there was no significant change in linear aggregation number, and hence the structure of the core remained constant. It is noteworthy that the micelles grown in ethyl acetate were slightly shorter than those grown in $n$ heptane and $n$-hexanes after $24 \mathrm{~h}$ (1440 min, Figure $4 \mathrm{~b})$, but after 1 month the final micelle lengths were the same within error (Figure S10). 
a)

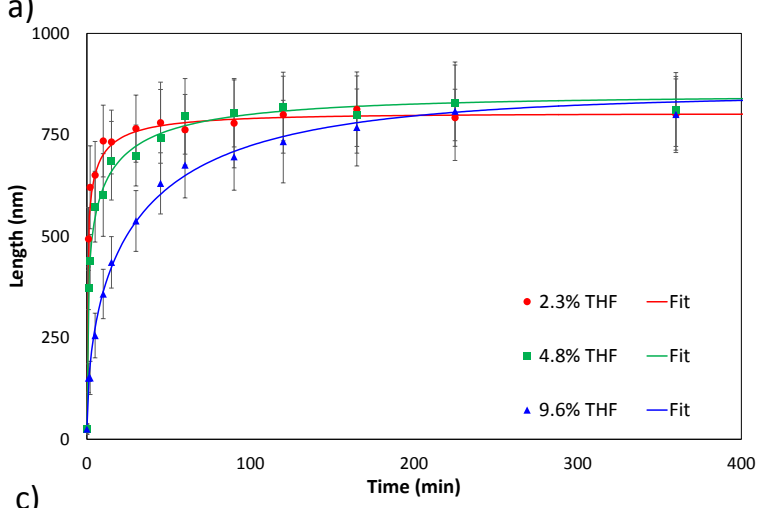

c)

\begin{tabular}{|c|c|c|c|c|c|c|}
\hline $\begin{array}{c}\text { THF } \\
(\%)\end{array}$ & $\begin{array}{c}\mathbf{A} \\
(\mathbf{n m})\end{array}$ & $\begin{array}{c}\text { Error } \\
(\mathbf{n m})\end{array}$ & $\mathbf{k}^{\mathbf{1}\left(\mathbf{s}^{-1}\right)}$ & Error $\left(\mathbf{s}^{-\mathbf{1}}\right)$ & $\mathbf{b}$ & Error \\
\hline 2.3 & 790 & 12 & $1.56 \times 10^{-2}$ & $3.3 \times 10^{-3}$ & 0.31 & 0.04 \\
4.6 & 832 & 14 & $3.04 \times 10^{-3}$ & $3.9 \times 10^{-4}$ & 0.35 & 0.02 \\
9.7 & 855 & 24 & $4.57 \times 10^{-4}$ & $5.9 \times 10^{-4}$ & 0.55 & 0.03 \\
\hline
\end{tabular}

b)

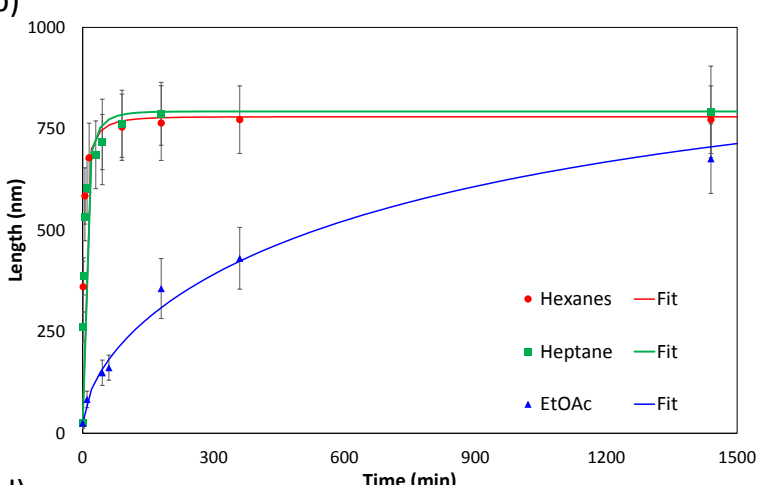

d)

\begin{tabular}{|c|c|c|c|c|c|c|}
\hline Solvent & $\mathbf{A}(\mathbf{n m})$ & $\begin{array}{c}\text { Error } \\
(\mathbf{n m})\end{array}$ & $\mathbf{k}^{\mathbf{\prime}}\left(\mathbf{s}^{-\mathbf{1}}\right)$ & Error $\left(\mathbf{s}^{-1}\right)$ & $\mathbf{b}$ & Error \\
\hline$n$-heptane & 734 & 8 & $6.32 \times 10^{-3}$ & $5.0 \times 10^{-4}$ & 0.49 & 0.03 \\
$n$-heptane & 748 & 16 & $3.45 \times 10^{-3}$ & $3.4 \times 10^{-4}$ & 0.54 & 0.06 \\
EtOAc & 928 & 32 & $1.75 \times 10^{-5}$ & $2.7 \times 10^{-6}$ & 0.62 & 0.03 \\
\hline
\end{tabular}

Figure 4: Lengths of $\mathrm{PFS}_{63}-b-\mathrm{PDMS}_{513}$ micelles as a function of time, monitored over a period of a) 6 $\mathrm{h}$ and b) $24 \mathrm{~h}$ after the addition of unimer to $\mathrm{PFS}_{63}-b$ - $\mathrm{PDMS}_{513}$ seed micelles, $\left(L_{\mathrm{n}}=25 \mathrm{~nm}, L_{\mathrm{w}} / L_{\mathrm{n}}=\right.$ 1.25) for a) variable percentage THF and b) variable selective solvent. c), d) Table of kinetic data for a) variable percentage THF, b) variable selective solvent, respectively. a, b) Error bars $= \pm \sigma$ (standard deviation) of the micelle $L_{\mathrm{n}}$. c, d) Standard errors for the values $A, k$, and $b$ obtained from the fit of Eq.8 to data.

\subsection{Effect of PFS degree of polymerization}

To investigate the effect the degree of polymerization of the PFS core has on the micelle growth rate, kinetic experiments were also performed with the BCPs, $\mathrm{PFS}_{63}-b-\mathrm{PDMS}_{513}$ and $\mathrm{PFS}_{49}-b-$ PDMS $_{504}$ (block ratios 1:8 and 1:10, respectively). These BCPs were selected as they have very similar degrees of polymerization for the corona-forming block (difference $<2 \%$ ), but $\mathrm{PFS}_{49}-b$ $\mathrm{PDMS}_{504}$ has a core-forming PFS block which has a degree of polymerization $22 \%$ lower than for $\mathrm{PFS}_{63}-b-\mathrm{PDMS}_{513}$. Reducing the PFS degree of polymerization not only reduced the micelle growth rate (from $k^{\prime}=1.16 \pm 0.08 \times 10^{-4} \mathrm{~s}^{-1}$ to $k^{\prime}=4.6 \pm 0.7 \times 10^{-6} \mathrm{~s}^{-1}$ ), but also resulted in much shorter micelles being formed $\left(L_{\mathrm{n}}=2690 \pm 253 \mathrm{~nm}\right.$ and $1426 \pm 134 \mathrm{~nm}$ for $\mathrm{PFS}_{63}-b-\mathrm{PDMS}_{513}$ and $\mathrm{PFS}_{49}-b-\mathrm{PDMS}_{504}$, respectively) (Figure 5). We viewed this as a likely consequence of the linear aggregation number being different for the two types of micelle on account of the different BCPs employed. To investigate this hypothesis further, solution SAXS/WAXS was performed on the final micelles grown from 
$\mathrm{PFS}_{63}-b-\mathrm{PDMS}_{513}$ and $\mathrm{PFS}_{49}-b-\mathrm{PDMS}_{504}$. These revealed a slight increase in core radius from $3.8 \mathrm{~nm}$ to $4.0 \mathrm{~nm}$ on reducing the PFS length from $\mathrm{DP}_{\mathrm{n}}=63$ to 49 (Figure S11 and Table S4), and no significant change in the associated core structure. The linear aggregation numbers are therefore 2.5 chains/nm and 3.5 chains/nm for $\mathrm{PFS}_{63}-b-\mathrm{PDMS}_{513}$ and $\mathrm{PFS}_{49}-b-\mathrm{PDMS}_{504}$, respectively. This increase in $N_{\text {agg }}$ of $40 \%$, however, does not fully account for the $47 \%$ reduction in final micelle length, and the reason for this discrepancy remains unclear. Nonetheless, the kinetic data demonstrate that reducing the PFS core length by an average of 14 repeat units caused the rate constant to be reduced by a factor of 25 from a $k^{\prime}$ value of $1.16 \pm 0.08 \times 10^{-4} \mathrm{~s}^{-1}$ for $\mathrm{PFS}_{63}-b-\mathrm{PDMS}_{513}$ to $4.6 \pm 0.7 \times 10^{-6} \mathrm{~s}^{-1}$ for $\mathrm{PFS}_{49}-b$ $\mathrm{PDMS}_{504}$. It is also noteworthy that different $b$ values were obtained from the fits $(b=0.60 \pm 0.01$ and $0.53 \pm 0.02$ for $\mathrm{PFS}_{63}-b-\mathrm{PDMS}_{513}$ and $\mathrm{PFS}_{49}-b-\mathrm{PDMS}_{504}$, respectively).

a)

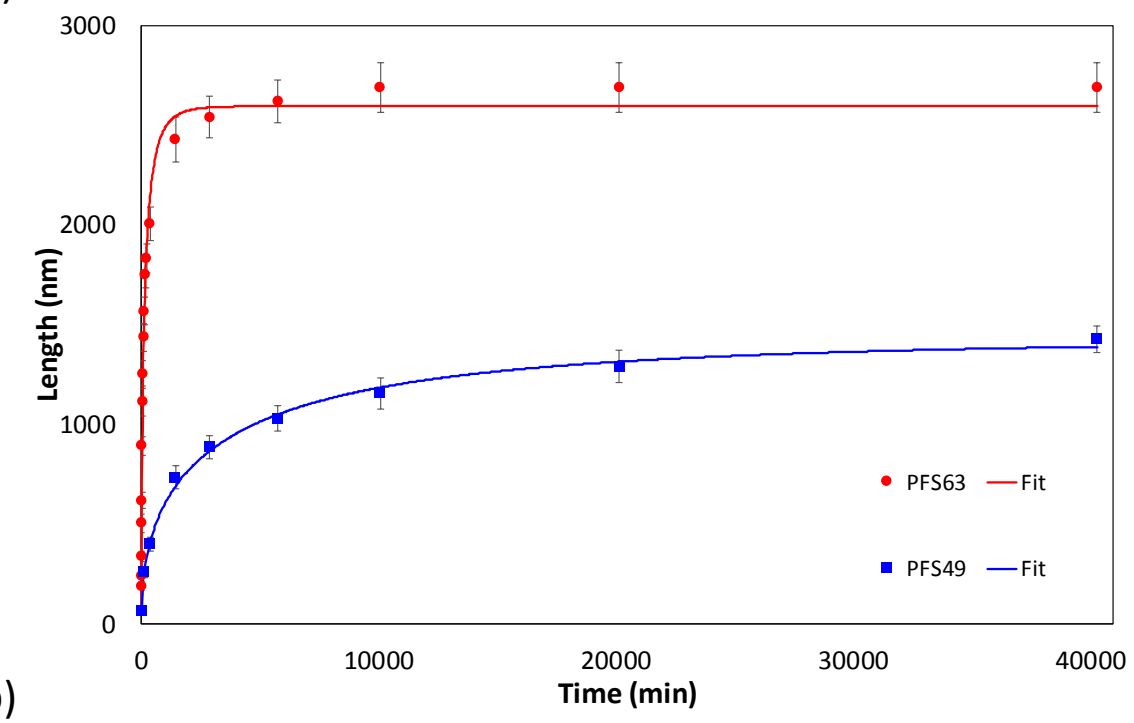

\begin{tabular}{|c|c|c|c|c|c|c|}
\hline PFS Length & $\mathbf{A}(\mathbf{n m})$ & Error $(\mathbf{n m})$ & $\mathbf{k}^{\prime}\left(\mathbf{s}^{-1}\right)$ & Error $\left(\mathbf{s}^{-1}\right)$ & $\mathbf{b}$ & Error \\
\hline $\mathrm{PFS}_{63}-b-\mathrm{PDMS}_{513}$ & 2520 & 42 & $1.16 \times 10^{-4}$ & $7.8 \times 10^{-6}$ & 0.60 & 0.01 \\
$\mathrm{PFS}_{49}-b-\mathrm{PDMS}_{504}$ & 1376 & 45 & $4.59 \times 10^{-6}$ & $6.7 \times 10^{-7}$ & 0.53 & 0.02 \\
\hline
\end{tabular}

Figure 5: a) Lengths of PFS- $b$-PDMS micelles as a function of time, monitored over a period of 4 weeks after the addition of unimer to $\mathrm{PFS}_{63}-b-\mathrm{PDMS}_{513}$ seed micelles $\left(L_{\mathrm{n}}=57 \mathrm{~nm}, L_{\mathrm{w}} / L_{\mathrm{n}}=1.11\right)$. b) Table of kinetic data for changing PFS core length. a) Error bars $= \pm \sigma$ (standard deviation) of the micelle $L_{\mathrm{n}}$. b) Standard errors for the values $A, k^{\prime}$, and $b$ obtained from the fit of Eq. 8 to data. 


\section{Monitoring micelle growth using super-resolution fluorescence microscopy}

It is important to verify that the data we have obtained from the TEM analysis of dried samples characterizing the growth of $\mathrm{PFS}_{63}-b$ - $\mathrm{PDMS}_{513}$ cylindrical micelles is representative of the CDSA process that occurs in solution. It has already been established for fully assembled micelles that the super-resolution techniques STED and SMLM provide comparable results to TEM. ${ }^{53}$ However, for the kinetics experiments all techniques were performed with high concentrations of unassembled unimer at early time points, which could, in principle, add to the micelle termini during the drying process. We therefore followed the micelle growth using SRFM as a solution-based technique to validate the trends obtained from TEM experiments. We have recently established protocols for use in organic media with the $\mathrm{BCP} \mathrm{PFS}_{56}-b-\mathrm{PDMS}_{775} / \mathrm{DYE}_{20}{ }^{53}$ For both techniques, short fluorescent seed micelles were prepared from BCPs 3\% labelled with the appropriate dye, STAR635 (STED) and CAGE635 (SMLM). The fluorescent seed micelles were longer $\left(L_{\mathrm{n}}=\right.$ ca. 600 $\mathrm{nm})$ than those typically used $\left(L_{\mathrm{n}}=25-57 \mathrm{~nm}\right)$ to aid visualization of the structures during the experiments, particularly at the early time points where the unimer concentration remains relatively high, which limits the signal to background ratio. Fluorescently labelled $\mathrm{BCP}$ unimer (dye = STAR635 single colour STED, CAGE500 for dual-colour SMLM) was added to the short fluorescent seed micelles and aliquots were taken from the solution and analyzed by STED, SMLM and TEM (Figure 6 and S12).
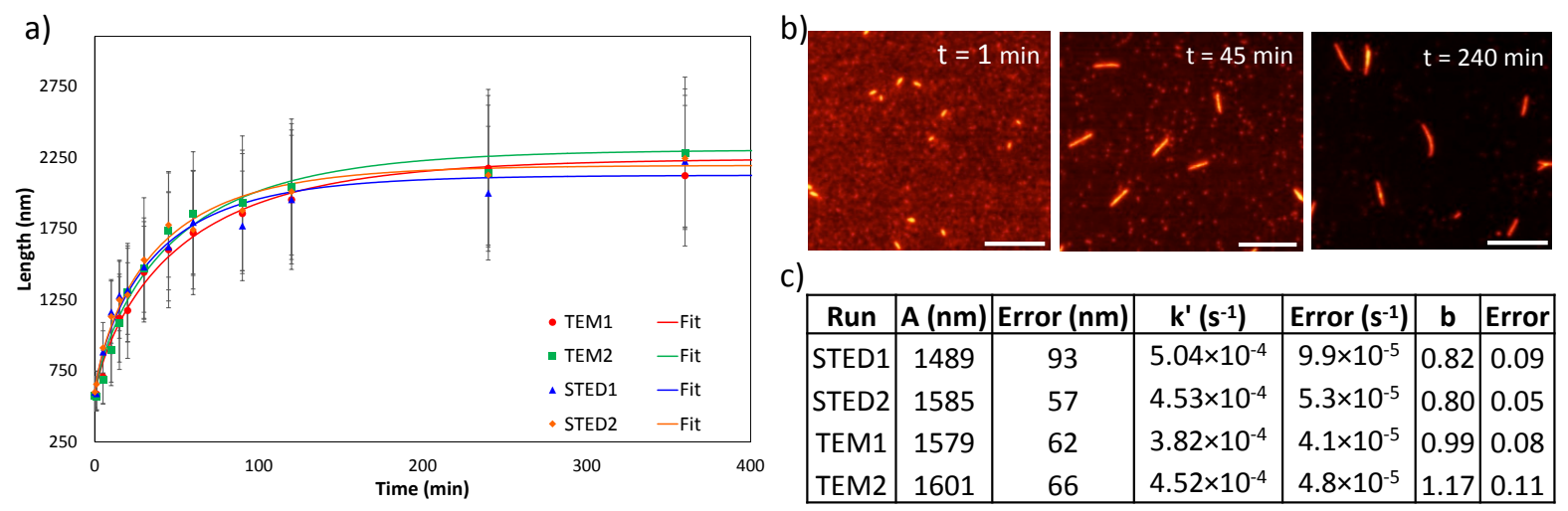

Figure 6: a) Plot of micelle length against time for TEM run 1 and 2 and STED run 1 and 2, monitored over a period of $6 \mathrm{~h}, \mathrm{~b}$ ) representative STED images at time points $1 \mathrm{~min}, 45 \mathrm{~min}$ and 240 min. Scale bars $=4.8 \mu \mathrm{m}$. c) Table of kinetic data for STAR635 BCP analyzed by STED and TEM. a) 
Error bars $= \pm \sigma$ (standard deviation) of the micelle $L_{\mathrm{n}}$. c) Standard errors for the values $A, k^{\prime}$, and $b$ obtained from the fit of Eq.8 to data.

For the STED/TEM kinetics experiments, all $k$ ' values are within error of each other, however, the $b$ values obtained from the data fitting for these experiments show quite significant discrepancies between the runs analyzed using STED and those employing TEM. The $b$ values from the STED runs are self-consistent (ca. 0.8), but do not agree with the TEM experiments, which provide much larger $b$ values $(1.0$ - 1.1). Furthermore, these contradict the $b$ values obtained $(0.57-$ 0.6) for the self-assembly of the non-dye-labelled BCP (Section 3.3). Inspection of the raw TEM data obtained for both the unlabelled and labelled PFS- $b$-PDMS experiments indicate that PFS $_{56}-b$ $\mathrm{PDMS}_{775} / \mathrm{STAR} 635_{20}$ produces micelles with higher dispersities $(\mathrm{PDI}=1.2-1.3)$ than $\mathrm{PFS}_{63}-b$ $\mathrm{PDMS}_{513}(\mathrm{PDI}=1.1-1.2)$. This increase in polydispersity increases the error associated with the length at each time point in the series, and therefore also the uncertainty in the fit. Repeating the fit of the data, but without weighting for the standard deviation of the micelle lengths produced $b$ values which were all 0.9 or lower. This indicates the significant role that the errors play in determining the $b$ values obtained, especially given the modest change in dispersity between samples. Nonetheless, even when the error weighting is removed, the STED and TEM $b$ values are still not in agreement, and this could be due to the lower resolution of the former effecting the accuracy of the measurement at early time points (i.e. shorter lengths). We also studied the micelle growth kinetics using two-colour SMLM (Figure S12 and S13), however, like the STED/TEM results, the techniques were inconsistent with each other, and the TEM data also differed from that obtained with unlabelled BCP. Although consideration of the STED data alone confirmed the non-first order behaviour of CDSA with respect to unimer $(b \neq 1)$, as determined by TEM analysis, the necessity for dye-labelled BCP (albeit at only $3 \%$ ) clearly complicates the self-assembly process. The exact role of the dye is currently unclear, but it evidently increases the rate of addition $\left(k^{\prime}=4.53 \pm 0.53 \times 10^{-4}\right.$ and $1.81 \pm 0.19 \times 10^{-4} \mathrm{~s}^{-1}$ for with and without dye, respectively), and also the length dispersity of the sample. 


\section{Discussion}

An investigation of the proposed differential rate equation for living CDSA (Eq. 1), by the method of initial rates, yielded reaction orders for $[U]$ and $[S]$ of $1.16 \pm 0.25$ and $-0.75 \pm 0.05$, respectively. Although the estimate of the former was consistent with the first-order behavior expected by analogy to a living covalent polymerization, the zero-order dependence on $[S]$ expected for $L(\mathrm{t})$ was not observed. $L(\mathrm{t})$, however, exhibited more a more complex relationship to both $[U]$ and $[S]$ when the whole duration of the reaction was considered. The length of $\mathrm{PFS}_{63}-b$-PDMS ${ }_{513}$ micelles observed during the self-assembly process as a function of time was therefore best modelled by a stretched exponential function (Eq. 8). In nature, stretched exponential functions have been successfully used to model processes that required a certain protein conformation to be obtained, but which may be achieved from any number of non-functional alternatives. This gives rise to a distribution of activation energies, and thus also to a distribution of kinetic rates, where the parameter $b$ (Eq. 8) is related to the width of the distribution. The crystallization of unimer onto the termini of the growing micelle would require the polymer in solution, and at the surface of the micellar core, to adopt a limited number of all the possible conformations, many of which will be energetically similar and accessible at ambient temperature. This situation would give rise to the distribution of activation energies required for the observed stretched exponential relationship of $L$ with respect to $t$. It should be noted that there is no requirement for molecular weight polydispersity in this explanation, only that the molecular weight is high enough for energetically similar conformations to be available.

It is evident from the experiments performed at different temperatures that increasing the temperature results in a reduced rate constant $\left(k^{\prime}\right)$. This is consistent with reports that the linear growth rate of homopolymer crystals decreased upon lowering the extent of supercooling, ${ }^{63}$ and may also be due to increased solubility of the core-forming block on increasing the temperature. However, the different temperature kinetic experiments also revealed that altering the self-assembly temperature effects the dimensions of the final cylindrical micelles in a similar manner to that observed for homopolymer crystals. ${ }^{64}$ Cylindrical micelles grown at higher temperatures were shorter in length with larger core radii, and with a higher linear aggregation number $\left(1.9\right.$ chains/nm at $5{ }^{\circ} \mathrm{C}$ compared to 3.3 chains $/ \mathrm{nm}$ at $42{ }^{\circ} \mathrm{C}$ ). It is noteworthy that studies of the annealing of $\mathrm{PI}_{637}-b-\mathrm{PFS}_{53}$ cylindrical 
micelles in solution revealed no thickening of the micellar core at temperatures below $60{ }^{\circ} \mathrm{C} .{ }^{65}$ These experiments therefore demonstrate that it is only when growth occurs at elevated temperatures that the micelle structure changes.

The kinetic experiments at different temperatures also allowed us to obtain information regarding the thermodynamics of the activation parameters involved for the living CDSA of $\mathrm{PFS}_{63}-b$ PDMS $_{513}$ micelles through an Eyring plot. Both the entropic and enthalpic terms were negative, which is expected due to the increased ordering of the core-forming PFS BCP chains upon crystallization and the exothermic nature of crystallization, respectively.

The solvent composition plays an important role in the rate of micelle growth. Altering the solvent composition so that it is more favourable for the PFS core-forming block, either by increasing the amount of common solvent, or through using a selective solvent that has a solubility parameter closer to that of PFS (e.g. using EtOAc instead of $n$-hexanes) causes a reduction in the rate constant. This trend underscores how any parameter that reduces the propensity for the PFS segment to precipitate from solution and crystallize on the termini of the growing micelle reduces the micellar growth rate.

It has been reported that altering the overall composition of PFS-containing micelles effects the dimensions of the resulting cylindrical micellar structure, ${ }^{55}$ but no comment was made as to how this might affect the rate of growth. In this experiment, it was found that reducing the number average degree of polymerization of the PFS segment by $22 \%$ (14 monomer units) from $\mathrm{PFS}_{63}$ to $\mathrm{PFS}_{49}$, whilst keeping the length of the corona block approximately the same $(<2 \%$ decrease $)$, resulted in a rate constant $\left(k^{\prime}\right) 25$ times smaller. It is known that the solubility of polymer chains decrease as the degree of polymerization increases and, therefore, it is expected that the PFS block will be less soluble in hexane in the BCP with the longer PFS core-forming segment than that with the shorter block. Furthermore, the equilibrium melting point, $T_{\mathrm{m}}$, will increase with molecular weight, leading to a larger degree of supercooling for the BCP with the longer PFS block, and this is reported to increase the linear crystal growth rate. ${ }^{63}$ Increasing the length of the PFS segment has also been shown to decrease the linear aggregation number, and hence increase the final length of the resulting micelles. An implication of chains of different lengths adding at different rates would be the establishment of a 
continuum of rates over the molecular weight distribution of the sample, which could give rise to the observed stretched exponential behaviour. We therefore modelled micelle growth, $L(\mathrm{t})$, using an initial Zimm-Schulz distribution of molecular weights, and a scaling factor relating the change in $k$ ' per unit degree of polymerization (see Supporting Information, page 25 for more details). Using the experimentally determined PDI for the PFS block (1.04) only afforded the typically observed $b$ value (ca. 0.6) for scaling powers between 4 and 5, and these are far less than the value of 12 observed between the change in $\mathrm{DP}_{\mathrm{n}}$ for the core-forming block and corresponding change in $k$ '. However, the range of molecular weights constituting the majority of each copolymer sample $\left[\sigma\left(M_{\mathrm{n}}\right)=2373\right.$ and $3051 \mathrm{~g} \mathrm{~mol}^{-1}$ for $\mathrm{PFS}_{49}$ and $\mathrm{PFS}_{63}$, respectively] is narrower that the separation between $\mathrm{PFS}_{49}-b$ $\mathrm{PDMS}_{504}$ and $\mathrm{PFS}_{63}-b-\mathrm{PDMS}_{513}\left[\Delta M_{\mathrm{n}}(\mathrm{PFS})=3390 \mathrm{~g} \mathrm{~mol}^{-1}\right]$. This may mean that more subtle changes in $k^{\prime}\left(\mathrm{DP}_{\mathrm{n}}\right)$ exist within a relatively monodisperse copolymer sample, and this is lost on studying two more disparate examples. Nonetheless, this analysis clearly cannot discount a role for core-forming block polydispersity as part of the reason for stretched exponential growth kinetics. It should also be noted that $\mathrm{PFS}_{63}-b-\mathrm{PDMS}_{513}$ with the longer PFS segment added at a faster rate than $\mathrm{PFS}_{49}-b$ $\mathrm{PDMS}_{504}$, which has a shorter PFS segment, which is the opposite to what would be expected if this were a diffusion limited process.

Previous work has demonstrated how the seed structure at the low length limit ( $c a .20 \mathrm{~nm}$ ) differs from that of the resulting micelle, and even the parent micelle from which it is derived. ${ }^{66}$ This suggests that it is possibly simplistic to expect totally symmetric growth from either side of the seed, and growth from seeds of all sizes to be the same. The seed size, however, appears to have modest influence on the growth rate with $k^{\prime}\left(9.8 \pm 1.5 \times 10^{-5} \mathrm{~s}^{-1}\right)$ for the longest seed size $(915 \mathrm{~nm})$ decreasing below the $3 \sigma$ confidence limit of that of the shortest $\left(k^{\prime}=4.61 \pm 0.65 \times 10^{-4} \mathrm{~s}^{-1}\right.$ for $\left.L_{\mathrm{n}}(\mathrm{seed})=25 \mathrm{~nm}\right)$. Nonetheless, the similarity of $k^{\prime}$ values $\left(6.10 \pm 0.42 \times 10^{-4}\right.$ and $\left.3.22 \pm 0.56 \times 10^{-4} \mathrm{~s}^{-1}\right)$ when equal amounts of unimer were added to seeds of $L_{\mathrm{n}}=25$ and $493 \mathrm{~nm}$, respectively, suggests that the short seeds are not unusual from a kinetics standpoint (see Supporting Information Figures S14-16 and Table S2).

The in situ experiments performed using SRFM techniques demonstrated how the stretched exponential also characterizes the observed growth process in solution, validating the data obtained 
from the TEM experiments. In these experiments, despite only being present on $3 \%$ of the corona, the nature of the dye has an effect on the micellar growth rate. The STAR635 dye-labelled BCP has a faster growth rate than the CAGE500-labelled BCP for the SMLM experiments. This effect of dye structure on the growth rate had been ascribed to the required modification of the corona-forming block altering amphiphilicity of the BCP ${ }^{67}$ Finally, for the SRFM experiments the sample preparation methods prevented the addition of any remaining unimer present in the sample to the micelle termini, and therefore effectively quenched the self-assembly reaction. This was convenient as image acquisition times are typically between 2-10 minutes, depending on the SRFM technique, and it is therefore important that growth is halted prior to analysis.

\section{Conclusion}

In summary, we have probed the growth kinetics of living CDSA using PFS - $b$-PDMS BCPs. We discovered that a range of parameters affect the micellar growth rate including concentration, temperature, the nature of the solvent medium, and $\mathrm{BCP}$ composition. It is noteworthy that the rate of self-assembly can be increased by either lowering the temperature, using poorer solvents for the crystalline PFS core-forming block, or by employing BCPs with longer core-forming PFS segments. Data fitting also enabled us to determine that the analogy of living CDSA to a living covalent polymerization of molecular monomers does not apply to the reaction kinetics, and that the growth rate is neither first order in unimer nor in seed concentration. The deviation from first order kinetics could be modelled using a stretched exponential function and we postulate that this behavior results from a combination of the influences of polymer chain conformation and molecular weight polydispersity on the addition of unimer to the micelle termini. These two factors arise as a natural consequence of the increased complexity of synthetic $\mathrm{BCP}$ chains compared to their monodisperse, small molecule counterparts. Overall, these results provide important additional insight into living CDSA processes and also provide guidelines for optimizing the efficiency of experimental protocols that should be relevant to a growing variety of BCPs with crystalline core-forming blocks ${ }^{12}$ and analogous amphiphiles ${ }^{22}$ that can be used for seeded supramolecular polymerizations. 


\section{Acknowledgements}

C.E.B. thanks the Bristol Chemical Synthesis Centre for Doctoral Training, funded by the EPSRC for the provision of a $\mathrm{PhD}$ studentship. E. M. L acknowledges the EU for a Marie Curie postdoctoral fellowship. D.W.H. was supported by the EPSRC Bristol Cente for Functional Nanomaterials doctoral training grant [EP/G036780/1]. R. F. L., P. M. and C.F.K. acknowledge grants from the EPSRC, UK (grant EP/H018301/1, EP/L015889/1) and the Medical Research Council (grant MR/K015850/1). I.M. thanks the EU for an ERC Advanced Investigator Grant. TEM studies were carried out in the Chemistry Imaging Facility at UoB with equipment funded by UoB and EPSRC (EP/K035746/1). The authors would like to thank David J. Lunn, John R. Finnegan, and Jieshu Qian for helpful discussions and Dr. Torben Gädt for preliminary experiments on the micelle growth kinetics

\section{Author Contributions}

C.E.B. and E. M. L performed all experiments, data analysis and wrote the paper together with R. F. L., G. R.W. , C.F.K. and I. M. and additional scientific input was provided by D.W.H., G. G., and M. A. W. D. W. H performed the X-ray analysis and assisted with the data fitting along with R. F. L., P. M. and R. M. R. The STED and SMLM was performed by P. M. and R. F. L., respectively. C. F. K. and I. M. supervised the project.

\section{References}

(1) De Greef, T. F. A.; Smulders, M. M. J.; Wolffs, M.; Schenning, A. P. H. J.; Sijbesma, R. P.; Meijer, E. W. Chem. Rev. 2009, 109, 5687.

(2) Whitesides, G. M. Science 2002, 295, 2418.

(3) Schacher, F. H.; Rupar, P. A.; Manners, I. Angew. Chem. Int. Ed. 2012, 51, 7898.

(4) Mai, Y.; Eisenberg, A. Chem. Soc. Rev. 2012, 41, 5969.

(5) Wang, J.; Liu, K.; Xing, R.; Yan, X. Chem. Soc. Rev. 2016, 45, 5589.

(6) Hayward, R. C.; Pochan, D. J. Macromolecules 2010, 43, 3577. 
(7) Gröschel, A. H.; Walther, A.; Löbling, T. I.; Schacher, F. H.; Schmalz, H.; Müller, A. H. E. Nature 2013, 503, 247.

(8) Blanazs, A.; Armes, S. P.; Ryan, A. J. Macromol. Rapid Commun. 2009, $30,267$.

(9) Gröschel, A. H.; Müller, A. H. E. Nanoscale 2015, 7, 11841.

(10) Elsabahy, M.; Wooley, K. L. Chem. Soc. Rev. 2012, 41, 2545.

(11) Ge, Z.; Liu, S. Chem. Soc. Rev. 2013, 42, 7289.

(12) (a) Lazzari, M.; Scalarone, D.; Vazquez-Vazquez, C.; López-Quintela, M. A. Macromol. Rapid Commun. 2008, 29, 352. (b) Du, Z. X.; Xu, J. T.; Fan, Z. Q. Macromolecules 2007, 40, 7633. (c) He, W. N.; Zhou, B.; Xu, J. T.; Du, B. Y.; Fan, Z. Q. Macromolecules 2012, 45, 9768. (d) Zhang, J.; Wang, L. Q.; Wang, H.; Tu, K. Biomacromolecules 2006, 7, 2492. (e) Schmalz, H.; Schmelz, J.; Drechsler, M.; Yuan, J.; Walther, A.; Schweimer, K.; Mihut, A. M. Macromolecules 2008, 41, 3235. (f) Yin, L.; Lodge, T. P.; Hillmyer, M. A. Macromolecules 2012, 45, 9460. (g) Schmelz, J.; Karg, M.; Hellweg, T.; Schmalz, H. ACS Nano 2011, 5, 9523. (h) Mihut, A. M.; Drechsler, M.; Möller, M.; Ballauff, M. Macromol. Rapid Commun. 2010, 31, 449. (i) Gilroy, J. B.; Lunn, D. J.; Patra, S. K.; Whittell, G. R.; Winnik, M. A.; Manners, I. Macromolecules 2012, 45, 5806. (j) Massey, J. A.; Temple, K.; Cao, L.; Rharbi, Y.; Raez, J.; Winnik, M. A.; Manners, I. J. Am. Chem. Soc. 2000, 122, 11577. (k) Kynaston, E. L.; Gould, O. E. C.; Gwyther, J.; Whittell, G. R.; Winnik, M. A.; Manners, I. Macromol. Chem. Phys. 2015, 216, 685. (1) Legros, C.; De Pauw-Gillet, M.-C.; Tam, K. C.; Taton, D.; Lecommandoux, S. Soft Matter 2015, 11, 3354. (m) Tong, Z.; Li, Y.; Xu, H.; Chen, H.; Yu, W.; Zhuo, W.; Zhang, R.; Jiang, G. ACS Macro Lett. 2016, 5, 867. (n) Yu, B.; Jiang, X.; Yin, J. Macromolecules 2014, 47, 4761. (o) Wu, J.; Weng, L.-T.; Qin, W.; Liang, G.; Tang, B. Z. ACS Macro Lett. 2015, 4, 593. (p) Rizis, G.; van de Ven, T. G. M.; Eisenberg, A. ACS Nano 2015, 9, 3627. (q) Lee, I.-H.; Amaladass, P.; Yoon, K.-Y.; Shin, S.; Kim, Y.-J.; Kim, I.; Lee, E.; Choi, T.-L. J. Am. Chem. Soc. 2013, 135, 17695. (r) Presa-Soto, D.; Carriedo, G. A.; de la Campa, R.; Presa Soto, A. Angew. Chem. Int. Ed. 2016, 55, 10102. (s) Lee, C.-U.; Smart, T. P.; Guo, L.; Epps, T. H.; Zhang, D. Macromolecules 2011, 44, 9574. (t) Yang, S.; Shin, S.; Choi, I.; Lee, J.; Choi, T.-L. J. Am. Chem. Soc. 2017, 139, 3082 (u) Tao, D.; Feng, C.; Cui, Y.; Yang, X.; Manners, I.; Winnik, M. A.; Huang, X. J. Am. Chem. Soc. 2017, 139, 7136-7139. (v) Arno, M. C.; Inam, M.; Coe, Z.; Cambridge, G.; Macdougall, L. J.; Keogh, R.; Dove, A. P.; O’Reilly, R. K. J. Am. Chem. Soc. 2017, 139, 16980 (w) Sun, L.; Pitto-Barry, A.; Kirby, N.; Schiller, T. L.; Sanchez, A. M.; Dyson, M. A.; Sloan, J.; Wilson, N. R.; O'Reilly, R. K.; Dove, A. P. Nat. Commun. 2014, 5, 5746. (x) Ganda, S.; Dulle, M.; Drechsler, M.; Förster, B.; Förster, S.; and Stenzel, M.H.Macromolecules, 2017, 50, 8544.

(13) Gilroy, J. B.; Gädt, T.; Whittell, G. R.; Chabanne, L.; Mitchels, J. M.; Richardson, R. M.; Winnik, M. A.; Manners, I. Nat. Chem. 2010, 2, 566.

(14) Hailes, R. L. N.; Oliver, A. M.; Gwyther, J.; Whittell, G. R.; Manners, I. Chem. Soc. Rev. 2016, 45, 5358 .

(15) Wang, X.; Guerin, G.; Wang, H.; Wang, Y.; Manners, I.; Winnik, M. A. Science 2007, 317, 644.

(16) Gädt, T.; Ieong, N. S.; Cambridge, G.; Winnik, M. A.; Manners, I. Nat. Mater. 2009, 8, 144.

(17) Hudson, Z. M.; Lunn, D. J.; Winnik, M. A.; Manners, I. Nat. Commun. 2014, 5, 3372. 
(18) Finnegan, J. R.; Lunn, D. J.; Gould, O. E. C.; Hudson, Z. M.; Whittell, G. R.; Winnik, M. A.; Manners, I. J. Am. Chem. Soc. 2014, 136, 13835.

(19) Petzetakis, N.; Dove, A. P.; O’Reilly, R. K. Chem. Sci. 2011, 2, 955.

(20) Schmelz, J.; Schedl, A. E.; Steinlein, C.; Manners, I.; Schmalz, H. J. Am. Chem. Soc. 2012, $134,14217$.

(21) Gwyther, J.; Gilroy, J. B.; Rupar, P. A.; Lunn, D. J.; Kynaston, E.; Patra, S. K.; Whittell, G. R.; Winnik, M. A.; Manners, I. Chem. Eur. J. 2013, 19, 9186.

(22) Seeded growth techniques analogous to living CDSA have also been extended to kinetically trapped supramolecular polymers and charge-terminated homopolymers see: (a) Zhang, W.; Jin, W.; Fukushima, T.; Saeki, A.; Seki, S.; Aida, T. Science 2011, 334, 340, (b) Ogi, S.; Sugiyasu, K.; Manna, S.; Samitsu, S.; Takeuchi, M. Nat. Chem. 2014, 6, 188. (c) Robinson, M. E.; Lunn, D. J.; Nazemi, A.; Whittell, G. R.; De Cola, L.; Manners, I. Chem. Commun. 2015, 51, 15921. (d) Bu, L.; Dawson, T. J.; Hayward, R. C. ACS Nano 2015, 9, 1878. (e) Ogi, S.; Stepanenko, V.; Sugiyasu, K.; Takeuchi, M.; Würthner, F. J. Am. Chem. Soc. 2015, 137, 3300. (f) Zhang, W.; Jin, W.; Fukushima, T.; Mori, T.; Aida, T. J. Am. Chem. Soc. 2015, 137, 13792. (g) Ma, X.; Zhang, Y.; Zhang, Y.; Liu, Y.; Che, Y.; Zhao, J. Angew. Chem., Int. Ed. 2016, 55, 9539. (h) Pal, A.; Malakoutikhah, M.; Leonetti, G.; Tezcan, M.; Colomb-Delsuc, M.; Nguyen, V. D.; van der Gucht, J.; Otto, S. Angew. Chem. Int. Ed. 2015, 54, 7852. (i) Fukui, T.; Kawai, S.; Fujinuma, S.; Matsushita, Y.; Yasuda, T.; Sakurai, T.; Seki, S.; Takeuchi, M.; Sugiyasu, K. Nat. Chem. 2016, 9, 493. (j) Greciano, E. E.; Sánchez, L. Chem. Eur. J. 2016, 22, 13724. (k) He, X.; Hsiao, M.-S.; Boott, C. E.; Harniman, R. L.; Nazemi, A.; Li, X.; Winnik, M. A.; Manners, I. Nat. Mat., 2017, 16, 481. (1) Görl, D.; Zhang, X.; Stepanenko, V.; Würthner, F. Nat. Commun. 2015, 6, 7009.

(23) Boott, C. E.; Gwyther, J.; Harniman, R. L.; Hayward, D. W.; Manners, I. Nat. Chem. 2017, 9, 785 .

(24) Hudson, Z. M.; Boott, C. E.; Robinson, M. E.; Rupar, P. A.; Winnik, M. A.; Manners, I. Nat. Chem. 2014, 6, 893.

(25) Qiu, H.; Gao, Y.; Boott, C. E.; Gould, O. E. C.; Harniman, R. L.; Miles, M. J.; Webb, S. E. D.; Winnik, M. A.; Manners, I. Science 2016, 352, 697.

(26) Rupar, P. A.; Chabanne, L.; Winnik, M. A.; Manners, I. Science 2012, 337, 559.

(27) Qiu, H.; Du, V. A.; Winnik, M. A.; Manners, I. J. Am. Chem. Soc. 2013, 135, 17739.

(28) Qiu, H.; Cambridge, G.; Winnik, M. A.; Manners, I. J. Am. Chem. Soc. 2013, 135, 12180.

(29) Qiu, H.; Russo, G.; Rupar, P. A.; Chabanne, L.; Winnik, M. A.; Manners, I. Angew. Chem. Int. Ed. 2012, 51, 11882 .

(30) Qiu, H.; Hudson, Z. M.; Winnik, M. A.; Manners, I. Science 2015, 347, 1329.

(31) Gilroy, J. B.; Rupar, P. A.; Whittell, G. R.; Chabanne, L.; Terrill, N. J.; Winnik, M. A.; Manners, I.; Richardson, R. M. J. Am. Chem. Soc. 2011, 133, 17056.

(32) Hsiao, M.-S.; Yusoff, S. F. M.; Winnik, M. A.; Manners, I. Macromolecules 2014, 47, 2361. 
(33) Nazemi, A.; He, X.; MacFarlane, L. R.; Harniman, R. L.; Hsiao, M.-S.; Winnik, M. A.; Faul, C. F. J.; Manners, I. J. Am. Chem. Soc. 2017, 139, 4409.

(34) Gustafsson, M. G. L.; Shao, L.; Carlton, P. M.; Wang, C. J. R.; Golubovskaya, I. N.; Cande, W. Z.; Agard, D. A.; Sedat, J. W. Biophys. J. 2008, 94, 4957.

(35) Ströhl, F.; Kaminski, C. F. Optica 2016, 3, 667.

(36) Hell, S. W.; Wichmann, J. Opt. Lett. 1994, 19, 780.

(37) Klar, T. A.; Jakobs, S.; Dyba, M.; Egner, A.; Hell, S. W. Proc. Natl. Acad. Sci. U. S. A. 2000, 97, 8206.

(38) Nespovitaya, N.; Mahou, P.; Laine, R. F.; Schierle, G. S. K.; Kaminski, C. F. Chem. Commun. 2017, 53, 1273.

(39) Rust, M. J.; Bates, M.; Zhuang, X. Nat. Methods 2006, 3, 793.

(40) Hess Girirajan T, Mason M, S. Biophys. J. 2006, 91, 4258.

(41) Betzig, E.; Patterson, G. H.; Sougrat, R.; Lindwasser, O. W.; Olenych, S.; Bonifacino, J. S.; Davidson, M. W.; Lippincott-Schwartz, J.; Hess, H. F. Science 2006, 313, 1642.

(42) Heilemann, M.; Van De Linde, S.; Schüttpelz, M.; Kasper, R.; Seefeldt, B.; Mukherjee, A.; Tinnefeld, P.; Sauer, M. Angew. Chem. Int. Ed. 2008, 47, 6172.

(43) Huang, B.; Wang, W.; Bates, M.; Zhuang, X. Science 2008, 319, 810.

(44) Pinotsi, D.; Buell, A. K.; Galvagnion, C.; Dobson, C. M.; Kaminski Schierle, G. S.; Kaminski, C. F. Nano Lett. 2014, 14, 339.

(45) Kaminski Schierle, G. S.; Van De Linde, S.; Erdelyi, M.; Esbjörner, E. K.; Klein, T.; Rees, E.; Bertoncini, C. W.; Dobson, C. M.; Sauer, M.; Kaminski, C. F. J. Am. Chem. Soc. 2011, 133, 12902.

(46) Roberti, M. J.; Fölling, J.; Celej, M. S.; Bossi, M.; Jovin, T. M.; Jares-Erijman, E. A. Biophys. J. 2012, 102, 1598.

(47) Duim, W. C.; Chen, B.; Frydman, J.; Moerner, W. E. ChemPhysChem 2011, 12, 2387.

(48) Ries, J.; Udayar, V.; Soragni, A.; Hornemann, S.; Nilsson, K. P. R.; Riek, R.; Hock, C.; Ewers, H.; Aguzzi, A. A.; Rajendran, L. ACS Chem. Neurosci. 2013, 4, 1057.

(49) Kaminski, C. F.; Kaminski Schierle, G. S. Neurophotonics 2016, 3, 041807.

(50) Gaspar, R.; Meisl, G.; Buell, A. K.; Young, L.; Kaminski, C. F.; Knowles, T. P. J.; Sparr, E.; Linse, S. Q. Rev. Biophys. 2017, 50, e6.

(51) Albertazzi, L.; van der Zwaag, D.; Leenders, C. M. A.; Fitzner, R.; van der Hofstad, R. W.; Meijer, E. W. Science 2014, 344, 491.

(52) Shim, S.-H.; Xia, C.; Zhong, G.; Babcock, H. P.; Vaughan, J. C.; Huang, B.; Wang, X.; Xu, C.; Bi, G.-Q.; Zhuang, X. Proc. Natl. Acad. Sci. 2012, 109, 13978. 
(53) Boott, C. E.; Laine, R. F.; Mahou, P.; Finnegan, J. R.; Leitao, E. M.; Webb, S. E. D.; Kaminski, C. F.; Manners, I. Chem. Eur. J. 2015, 21, 18539.

(54) Ni, Y.; Rulkens, R.; Manners, I. J. Am. Chem. Soc. 1996, 118, 4102.

(55) Hayward, D. W.; Gilroy, J. B.; Rupar, P. A.; Chabanne, L.; Pizzey, C.; Winnik, M. A.; Whittell, G. R.; Manners, I.; Richardson, R. M. Macromolecules 2015, 48, 1579.

(56) Qiu, H.; Gao, Y.; Du, V. A.; Harniman, R.; Winnik, M. A.; Manners, I. J. Am. Chem. Soc. 2015, 137, 2375.

(57) The linear aggregation can also be determined by static light scattering. Using this method a linear aggregation number of 2.5 chain $/ \mathrm{nm}$ was also obtained for the comparable BCP, $\mathrm{PFS}_{50^{-}}$ $b$-PDMS 285 . Cambridge, G.; Guerin, G.; Manners, I.; Winnik, M. A. Macromol. Rapid Commun. 2010, 31, 934.

(58) Odian, G. Principles of Polymerization, 4th ed.; John Wiley and Sons, 2004.

(59) Sanchez, I. C.; Colson, J. P.; Eby, R. K. J. Appl. Phys. 1973, 44, 4332.

(60) Doye, J. Polymer (Guildf). 2000, 41, 1519.

(61) Barton, A. F. M. CRC Handbook of Solubility Parameters and Other Cohesion Parameters, Second.; CRC Press, 1991.

(62) Kulbaba, K.; MacLachlan, M. J.; Evans, C. E. B.; Manners, I. Macromol. Chem. Phys. 2001, $202,1768$.

(63) Zhou, Y.; is, W. J. Phys. Chem. B 2013, 117, 3047.

(64) Xu, J.; Ma, Y.; Hu, W.; Rehahn, M.; Reiter, G. Nat. Mater. 2009, 8, 348.

(65) Guerin, G.; Rupar, P.; Molev, G.; Manners, I.; Jinnai, H.; Winnik, M. A. Macromolecules 2016, 49, 7004.

(66) The height by AFM of the seed micelles is significantly less than that for the parent micelles (see ref. 13, Figures S2 and S1, respectively). This suggests that some structural reorganization of the micelle occurs after prolonged ultrasound, but without any reduction in the fidelity of the seed for further growth.

(67) McDonough, R.; Cueto, R.; Phillies, G. D. J.; Russo, P. S.; Dorman, D.; Streletzky, K. A. Macromolecules 2015, 48, 7245 . 
TOC Image:
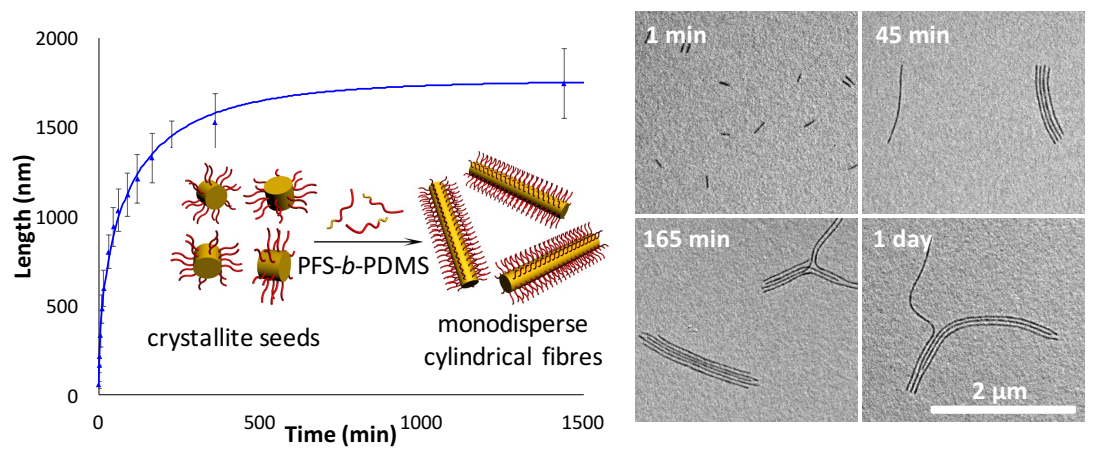